\title{
Simulation and Analysis on Characteristics of Lower-group Roadway Surrounding Rock under Deep Near Interval Coal Seam
}

\author{
ZHANG Peisen, WANG Hao, LIN Dongcai, KAN Zhonghui
}

(1 CMSE of Shandong University of Science and Technology Shandong Qingdao 2665902

Key Laboratory of Mine Disaster Prevention and Control Qingdao Shandong 266590)

\begin{abstract}
Based on the linear function between the maximum horizontal stress obtained by fitting the measured in-situ stress test result and buried depth, FLAC3D software was used in this paper to analyze the characteristics of lower-group roadway surrounding rock under the influence of multi-mining of deep nearly interval coal seam. The results showed that: There are relatively high stress concentration around roadway, especially on the left side and the roof, affected by space location during tunneling; The vertical stress and the maximum and minimum principal stresses of roadway surrounding rock are increasing, while the horizontal stress is decreasing during the mining of working face; During roadway excavation, Surrounding rock stress is asymmetry due to the asymmetry mining of near working faces and the multiple factors superposition affected by supporting pressure and original rock pressure, while both sides of the roadway are substantially symmetrical after the mining of working face.
\end{abstract}

Keyword : Deep, Near Interval, Excavate Roadway along Goaf, Characteristics of Surrounding Rock, Numerical Simulation

\section{Introduction}

Coal is the foundation of the national economy and social development, it is predicted that the proportion of coal in China's principal energy is still up about 50\% by 2050 . Underground mining is the main method in China, requiring a lot of underground roadway excavation. According to incomplete statistics, the former state-owned key coal roadway excavation length was $7598.4 \mathrm{~km}$, and more than $80 \%$ of roadways were coal roadway and semi coal-rock roadway in 2005 . 70 to $80 \%$ of roadway surrounding rock stability were strongly influenced by coal mining[1] C Coal mining causes redistribution of surrounding rock stress, not only giving rise to stress concentration on coal pillar around mining space, but also passing the stress into deep floor rock stratum $[2,3,4,5]$ 。 And with the increase of mining depth, surrounding rock pressure continues to grow, as well as more and more serious roadway deformation. It is not only makes a lot closer of the two ribs, roof subsidence, but also showed a strong floor heave[6,7,8]. Therefore, it is significant to analyze the characteristics of lower-group roadway surrounding rock under deep nearly 
interval coal seam for maintaining the stability and smooth as well as ensuring roadway mine construction and production safety.

\section{Project Overview}

Currently coal mining depth is nearly $800 \mathrm{~m}$ in Jinning II coal mine, reaching a mining depth of rock burst occurrence, and the main mining coal seam with the rock burst inclination. The study area is located in the bifurcation of No. 3 seam, mainly mining 3 up and 3down, as nearly distance coal mining. The above coal seam used fully mechanized mining, and the beneath used fully mechanized sublevel caving mining. The mining sequence is downward mining, and the mining sequence of working face is 113 up01 working face $\rightarrow 113$ down08 working face $\rightarrow 113$ up02 working face $\rightarrow 113$ down09 working face. Driving roadway along goaf in 113down09 track tunnel with thin coal pillar retaining, and designing the width of thin coal pillar is $3.5 \mathrm{~m}$ in 113 down08 goaf. During the mining process of adjacent working faces, supporting pressure distribution above the 113down09 working face are constantly changing, and not all above coal seams can be obtained leading to stress concentration in the remaining pillar area, which affects the stability of track tunnel of 113down09 working face. 113down09 track tunnel begins excavation after the mining of adjacent working face completes, at that time, overlying rock movement of goaf has not been stable as 113 down08 mining ends not long, therefore, the complex supporting pressure, forming during the track tunnel excavation, affects the roadway stability.113 down 09 and the adjacent working face layout are shown in Figure 1.

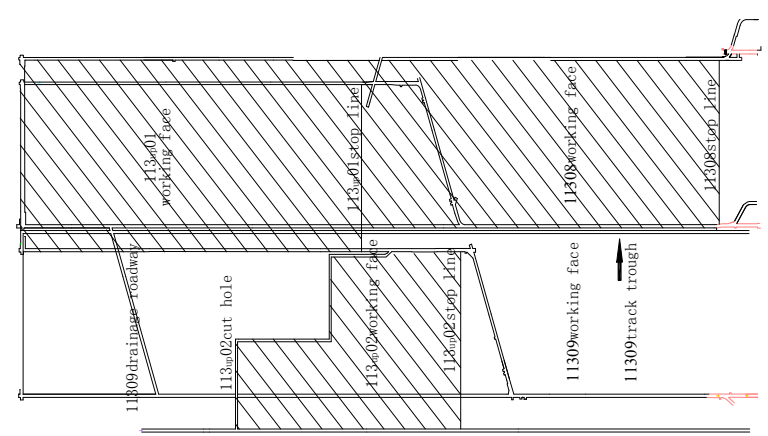

Fig. 1 Spatial relationships of working face layout

\section{Determination of In-situs Stress}

Combining stress measurement results of eleven mining area and the surrounding mining area, as shown in Table 1, the paper using regression analysis, gains the function between the maximum horizontal stress $\sigma_{\text {hmax }}$ and buried depth $\mathrm{H}$, that is, $\sigma_{\text {hmax }}=0.033 \mathrm{H}+1.908$, coefficient of determination $\mathrm{R}^{2}=0.668$. Its fitting curve is shown in Figure 2.

\begin{tabular}{ccccc}
\hline $\begin{array}{c}\text { Principal } \\
\text { stress }\end{array}$ & $\begin{array}{c}\text { measurem } \\
\text { ents/MPa }\end{array}$ & $\begin{array}{c}\text { Elev } \\
\text { ation } \\
{ }^{\circ}\end{array}$ & $\begin{array}{c}\text { Azim } \\
\text { uth/ }\end{array}{ }^{\circ}$ & $\begin{array}{c}\text { testing } \\
\text { depth/ } \\
\text { m }\end{array}$ \\
\hline$\sigma 1$ & 22.34 & 13.0 & 82.0 & 571 \\
$\sigma 1$ & 21.91 & 13.2 & 98.3 & 685 \\
$\sigma 1$ & 26.99 & 7.0 & 97.0 & 759 \\
$\sigma 1$ & 29.79 & 5.4 & 81.0 & 773 \\
\hline
\end{tabular}

Table 1 Stress of principal rock measurements under different testing depth 


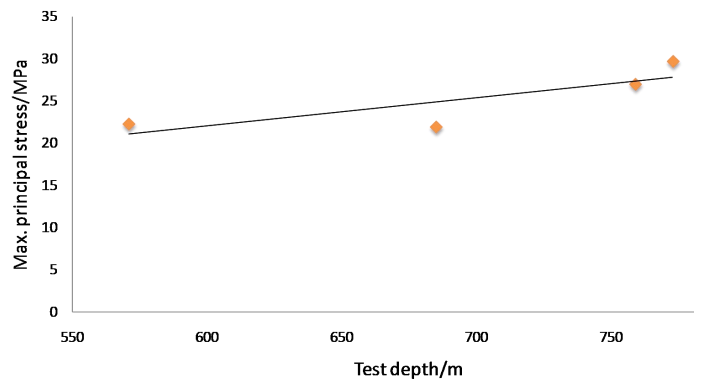

Fig. 2 Relationship curve between the maximum horizontal principal stress and buried depth

According to the above function, the maximum horizontal principal stress is $27.65 \mathrm{Mpa}$ when buried depth of 113down09 working face is $780 \mathrm{~m}$.

\section{Numerical Model}

Given many advantages of FLAC3D, the software was used to build the numerical model. According to the geological conditions, stratigraphic integrated histogram and spatial relationships of adjacent working faces in Jinning II coal mine, the simulation determined the upper boundary level-680m, the lower boundary level-820m, and laterally to both working face sidelines $100 \mathrm{~m}$. In order to obtain accurate results of the stress and displacement distribution, grids at the adjacent excavation area and coal pillar area were compacted, and specific grids generation is shown in Figure 3. Both sides of the model (horizontal direction) use horizontal displacement constraints, and the bottom of the model uses vertical and horizontal displacement constraints, and the load of the upper strata on the model boundary is approximately considered as uniformly distributed load $q$, i.e. Overburden weight $q=\gamma H$, and the selection of $q$ is related to thickness $H$. The Mohr-Coulomb model is adopted for numerical simulation, and the goaf and roadway using "Null" element.

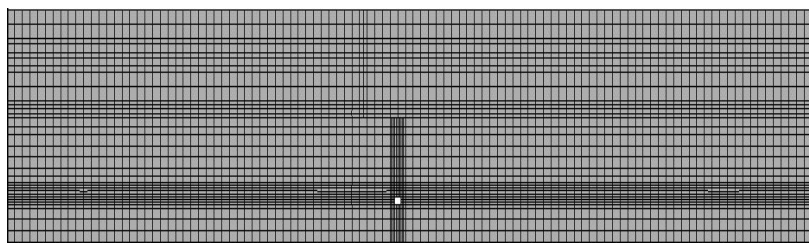

Fig. 3 Grids of model

\section{Analysis of Simulation Results}

In accordance with the model, adjacent working face of 113down09 are firstly mined to analyze the stress characteristics of overlying strata after mining face; Then simulate the excavation of track tunnel of 113down09 to analyze stress characteristics of roadway surrounding rock during the excavation process; 113down09 working face excavation is finally simulated to analyze stress characteristics of roadway surrounding rock during the mining process.

\subsection{Simulation Result during Roadway Excavation}

Before the track tunnel of 113down09 excavation, overlying rock collapse regularly after the mining of nearby working face, which has a great impact on 113down09 excavation. Figure 4-Figure 7 describe the impact of 113down08, 113up02 and 113up01 mining on track tunnel of 113 down09 excavation. 


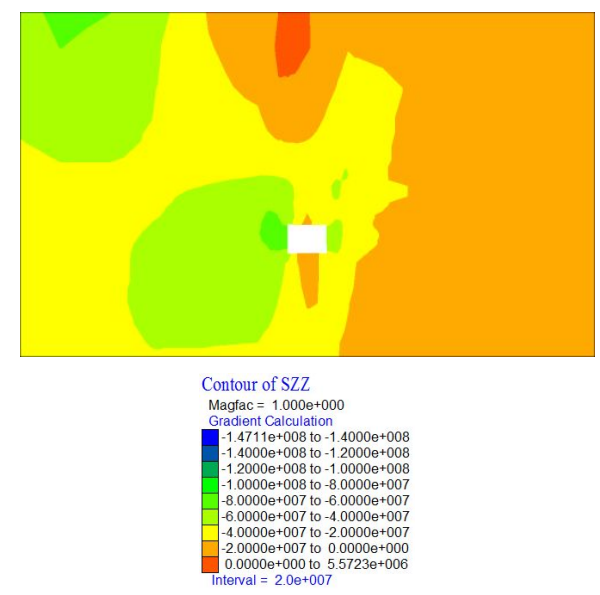

Fig. 4 Vertical stress distribution

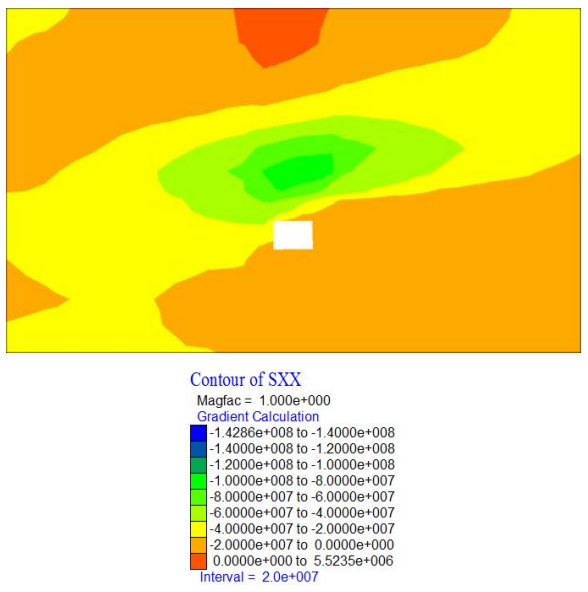

Fig. 5 Horizontal stress distribution

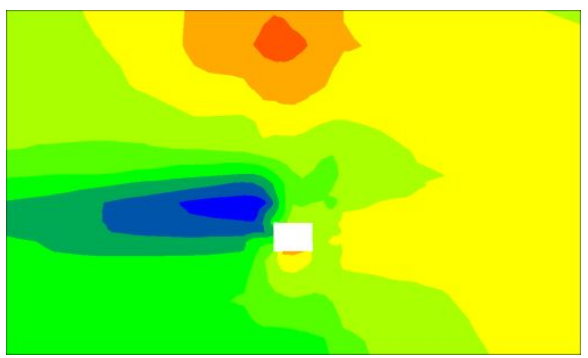

Contour of SMax

Magfac $=1.000 \mathrm{e}+000$

$3.4655 \mathrm{e}+007$ to $-3.0000 \mathrm{e}+007$

$-3.0000 \mathrm{e}+007$ to $-2.5000 \mathrm{e}+007$
$-25000 \mathrm{e}+007$ to $-2.0000 \mathrm{e}+007$

$-2.50000+007$ to $-2.000000+007$
$-2.0000 \mathrm{e}+007$ to $-1.5000 \mathrm{e}+007$

$-1.5000 \mathrm{e}+007$ to $-1.0000 \mathrm{e}+007$

$5.0000 \mathrm{e}+006$ to $0.0000 \mathrm{e}+000$

$0.0000 \theta+000$ to $5.00000+006$

Interval $=5.0 \mathrm{e}+006$

Fig. 6 Maximum principal stress distribution

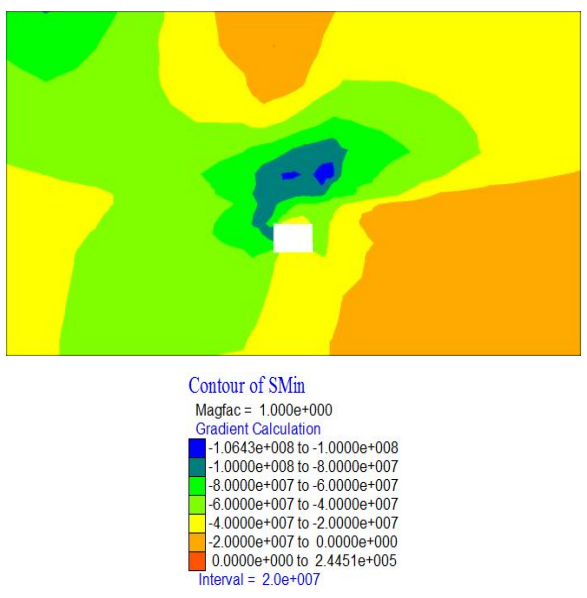

Fig. 7 Minimum principal stress distribution As can be seen from Figure 4 to Figure 7, the surrounding rock occurs stress concentration during roadway excavation. Figure 4 shows that vertical stress around the roadway is increasing. Stress concentration on the roadway left rib is more obvious due to the left pillar, while stress concentration on the right rib is small because of the right adjacent 113down08 goaf. Figure 5 shows that there is a large increased area of horizontal stress resulted from shear stress of margin stratum increasing by the mining of right working face. Figure 6 shows that the maximum principal stress is on the left side of the roadway. Figure 7 shows that the minimum principal stress is also on the left side of roadway, and relatively great, but the minimum principal stress concentration above the roadway is greater.

\subsection{Simulation Results during the Mining of Working Face}

The mining of 113down09 working face 
aggravates the deformation and failure of surrounding rock, and stress filed of 113down09 crossheading undergoes complex changes again. Figure 8-Figure 11 describe the stress characteristics of roadway surrounding rock during the mining of 113 down09 working face.

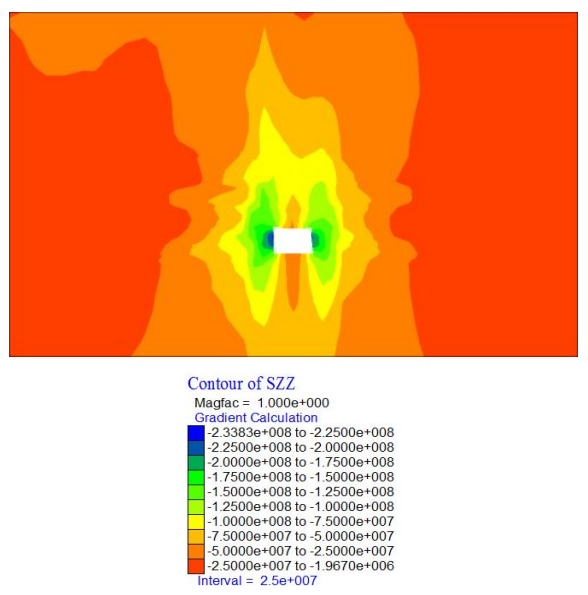

Fig. 8 Vertical stress distribution

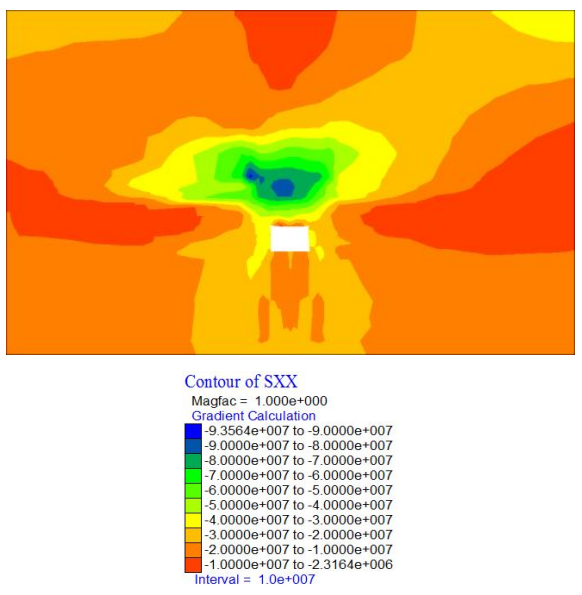

Figure 9 Horizontal stress distribution

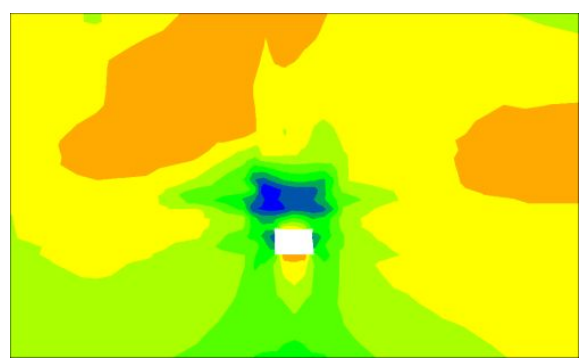

Contour of SMax

Magfac $=1.000 \mathrm{e}+000$

Gradient Calculation
$-3.9789 \mathrm{e}+007$ to $-3.5000 \mathrm{e}+007$

$0.00000+000$ to $2.7326 \theta^{+00}$

Figure 10 Maximum principal stress distribution

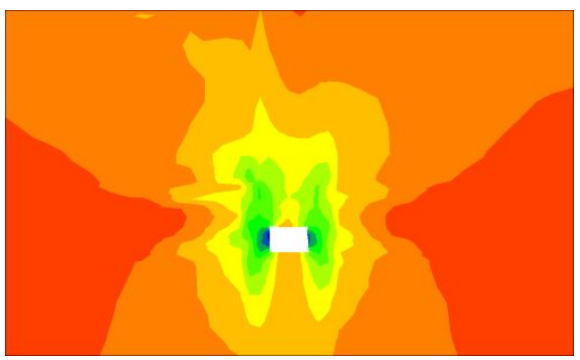

Contour of SMin Magfac $=1.000 \mathrm{e}+000$

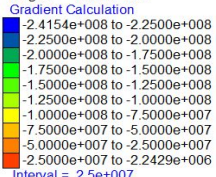

Figure 11 Minimum principal stress distribution

As can be seen from Figure 8 to Figure 11, surrounding rock stress concentration increases after the mining of 113 down 09 working face, and concentration area is roughly symmetrical distribution. Figure 8 shows that vertical stress concentration on roadway ribs is obviously intensified, and both sides of ribs are goaf, so stress concentration symmetrically distributes on both sides of the roadway. Figure 9 shows that horizontal stress concentration is on the upper side of track tunnel, and stress distribution is symmetrical as working faces of both roadway sides has completed mining. The shear stress of roof stratum decreases, so horizontal stress decreases more than that during 
excavation. Figure 10 shows that the maximum principal stress concentration transfers to the roadway roof, and relatively greater. Figure 11 shows that the minimum principal stress concentration area is symmetrically distributed on both sides of the roadway.

\section{Conclusions}

The FLAC3D software is used to simulate and analyze the surrounding rock characteristics during the excavation of track tunnel and mining of 113down09 working face. The following conclusions are drawn.

1)According to the actual measurements of in-situ stress, regression method is used to obtain the function between the maximum horizontal principal stress $\sigma$ hmax and buried depth H, i.e., $\sigma_{\text {hmax }}=0.033 \mathrm{H}+1.908$.

2) During the excavation of track tunnel, the right is completed 113down08 working face, and the left is uncompleted 113down09 working face, so relatively higher stress concentration is on the left side and the roof of the roadway because of the influence of spatial location. Therefore, there is safety hazard of rock burst occurring in such areas, and the monitoring and prevention of rock burst are necessary.

3 ) During the mining of working face, overlying strata movement intensifies, the plastic zone further develops, and stress distribution of working face changes, especially the stress distribution area of 113down09 track tunnel. Since both sides of roadway have been mined, stress distribution of both roadway sides is substantially symmetrical, vertical stress and the maximum and minimum principal stress are all increases, while horizontal stress decreases.

\section{Acknowledgment}

This research was supported in part by the Shandong University of Science and Technology and Key Laboratory of Mine Disaster Prevention and Control. It was also sponsored by the National Natural Foundation of China (No.51109124 and No.51379119) and New Teachers' Fund for Doctor Stations of Ministry of Education (No. 20113718120009) and 973 Plan Special Prophase Research (No. 2012CB72310401) and Construction of Special Funds for "Taishan Scholars" in Shandong Province and Coal Pillar Properties and Strata Control Innovation Team.

\section{References}

[1] Xie Wenbing, Shi Zhengfan, Ying Shaozhu. Stability analysis of surrounding rock masses of roadway under overhead mining [J]. Chinese Journal of Rock Mechanics and Engineering, 2004, 23(12):1986-1991.

[2] Chen Yanguang,Lu Shiliang. Strata Control around Coal Mine Roadways in China [M]. Xuzhou: China University of Mining and Technology Press, 1994.

[3] Zhang Jincai, Zhang Yuzhuo, Liu Tianquan. Rock Mass Seepage and water-inrush from coal floor $[\mathrm{M}]$. Beijing: Geosciences Press, 
1997.

[4] Peng Suping, Wang Jinan. Coal Mining above Confined Aquifer [M]. Beijing: China Coal Industry Publishing House, 2001.

[5] Jiang Jinquan, Feng Zengqiang, Han Jisheng. Classification Of Structural Stability of Surrounding Rocks of Roadway Affected by Overhead Mining and Decision Making of Support Parameters [J]. Chinese Journal of Rock Mechanics and Engineering, 1999, 18(1): 81-85.

[6] Liu Hanxi, Li Xuehua, Chen Xiuyou etc. Simulation on Instability Mechanism of Mining Induced Sensitive Floor Roadway $[\mathrm{J}]$. Journal of Mining \& Safety Engineering, 2007, 24(2): 253-257.

[7] He Manchao, Li Guofeng, Liu Zhe etc. Countermeasures Aiming at the Support for Crossing Roadway of Deeply Buried Soft Rocks in Xingan Coal Mine [J]. Journal of Mining \& Safety Engineering, 2007, 24(2): 127-131.

[8] He Manchao, Peng Tao, Chen Yijin. Large Deformation in Softrock Engineering [J]. Hydrogeology and Engineering Geology, 1994(5):5-9. 